\title{
Um Estudo de Caso sobre Luthieria em Campo Mourão
}

Recebido em 08.01.2016. Aprovado em 20.11.2016 Avaliado pelo sistema double blind review

\author{
Leandro Moreira Luz \\ professorleandromoreira@gmail.com \\ Faculdade Integrado de Campo Mourão - Campo Mourão - PR \\ Marcos de Matos Olioze \\ molioze79@gmail.com \\ Faculdade Integrado de Campo Mourão - Campo Mourão - PR \\ Rogério Silveira Tonet \\ rog.tonet@uol.com.br \\ Universidade Federal de Santa Catarina - Florianópolis - SC
}

\begin{abstract}
Resumo
A produção de um instrumento musical, desde a escolha da madeira até os últimos acabamentos e testes, na realidade é um todo interligado e indivisível. Desse "todo" produtivo, a visão analisadora e classificadora dos pesquisadores buscou extrair artificialmente o espírito empreendedor do artífice, que neste segmento é denominado Luthier, quando ele mergulha no mundo dos negócios e cria sua própria empresa com um toque específico e inovador para a região de Campo Mourão - PR. Mas, o que define um empreendedor? Há várias atribuições para o empreendedor: este pode ser aquele que é reconhecido por ter uma ousadia acima da média e a competência de transformar "algo" numa oportunidade de gerar riqueza e/ou, também, aquele que reúne em si qualidades como: iniciativa, visão, criatividade, coragem, firmeza, decisão, etc. $E$ foi o espelho dessas definições que fomentou o estudo de caso em tela, além da observação das variáveis utilizadas para driblar a restrição financeira: a criatividade, o espírito inovador e a visão de mercado que reúnem-se na empresa estudada. Desse modo, criou-se, então, a oportunidade de pesquisa científica sobre um empreendedor que no caminho entre a subjetividade das idéias e o alcance do mercado cria suas máquinas e sua tecnologia produtiva da mesma forma que um compositor mescla harmonia, melodia e ritmo em suas composições musicais.
\end{abstract}

Palavras-chaves: Empreendedor. Luthieria. Estudo de Caso.

\begin{abstract}
The production of a musical instrument, from choosing the wood to the final finishing and testing, is actually interlinked and indivisible, as a whole. From this productive "whole", the researchers, in an analyzer and classifier vision, artificially extract the enterprise spirit of the artificer, that in this segment is called Luthier, when he "dives" in the business world and creates his own company with in a specific way for the region of Campo Mourão - PR. But what defines an entrepreneur? _There are many definitions for entrepreneur. He can be one that is recognized as having an above-average courage and competence to turn "something" into an opportunity to create wealth, or in other words, the one which has some specific qualities, such as initiative, vision, creativity, courage, firmness, decision, etc.. It was the mirror of these settings that promoted the case study. The ways used to dribble the financial restriction, creativity, innovative spirit and market vision are present in the studied company. Without these productive raw materials, there would not be the others in the Luthier production. By the way, was created then, the opportunity for scientific research about an entrepreneur that, in the path between the subjectivity of the ideas and achievement of the market, creates its machines and its technology the same way as a composer mixes harmony, melody and rhythm in his song writings.
\end{abstract}

Keywords: Entrepreneur. Luthier. Case Study. 


\section{Introdução}

O ensejo empreendedor que fomenta o indivíduo a posicionar-se no trade-off_empresário/colaborador a favor do "próprio negócio" visando a concretização de oportunidades identificadas pelo agente em sua comunidade; a base produtiva repousada no estado de arte e no conhecimento tácito; e o espírito inovador em conjunto com a desenvoltura técnica/artística para a personificação e para a adaptação dos instrumentos/métodos de trabalho, são o fomento que alvitrou a produção do presente artigo. Desse modo, analisa-se aqui um tipo de empresa com uma característica totalmente específica: a Luthieria _ empresa que constrói, regula e restaura instrumentos de musicais de cordas como violões, violas, guitarras etc., isto é, empresa que detém a arte/tecnologia da construção e da manutenção de instrumentos musicais (CAMARGO e SCOPINHO, 2007).

Neste ínterim, o objetivo deste trabalho é demonstrar analogias entre o caso em concreto e a literatura básica sobre 0 tema "empreendedorismo" e, também, evidenciar os meandros que denotam este "empreendedorismo" do em questão que, neste caso em específico, é sinalizado pela maneira alternativa e inteligente que a empresa estudada utilizou e utiliza para driblar suas restrições técnicas e financeiras, de um modo que a tornou viável num mercado tipicamente artesanal de produtos customizados.

Portanto, o presente artigo foca em um Luthieria localizada na cidade de Campo Mourão - PR; e investiga as suas atividades. Para tanto, constitui-se de 3 seções, além dessa introdução: a seção 2 apresenta o referencial teórico dos principais autores que tratam a respeito do empreendedorismo, tecnologia, função de produção, administração da produção e mercados; a seção 3 exibe a metodologia das buscas dos dados para pesquisa; e, por fim, a seção 4 demonstra a análise de dados e discussões, seguidas da conclusão e referencias bibliográficas.

\section{A Luthieria e o Empreendedorismo}

É francesa a origem da palavra entrepreneur: "aquele que incentivava as brigas"; e nesta origem etimológica já se pode observar o intuito de deixar transparecer um espírito ousado e inquieto que estimulava a saída do indivíduo de um "estado de conforto" para um estado de inquietude/briga. Já no século XIX, Jean Baptist Say conceitua o empreendedor como 0 indivíduo que mobiliza recursos para uma área de maiores retornos e produtividade. Mais tarde, no século XX, Joseph Schumpeter coloca o empreendedor como o agente que renova ou revoluciona o processo "criativo-destrutivo" do capitalismo, desenvolvendo novas tecnologias e utilizando as já existentes de forma inovadora. E neste comenos, Peter Ferdinand Drucker, considerado o "pai da administração moderna", confirma as definições de Say e Schumpeter colocando o empreendedor como aquele que aproveita as oportunidades para criar mudanças (DRUKER, 2000).

Nesta toada, a busca do trabalho sem rotina e repetição que demanda responsabilidade (mas causa satisfação), além do alto nível de disposição, perseverança e imaginação para transformar uma simples idéia, difícil até de ser mensurada, em algo definido e concreto, sinalizam um empreendedor segundo Byrley e Muzyka (2001). Esta necessidade criativa pode virar alvo de estudo no âmbito dos negócios se houver a capacidade de identificar, capturar e explorar as oportunidades de mercado trazendo em seu bojo a pergunta:_O que, exatamente, leva o indivíduo a ser empreendedor? Sem tentar esgotar as possibilidades de repostas, pode-se dizer que, neste caso em especial, o indivíduo necessita de uma predisposição em: i) inovar; ii) Criar; e, por último: iii) Ter "subjetividade" para um trabalho que demanda ousadia e experimentação. Além de que, obviamente, para um empreendedor é fundamental a predisposição para identificar oportunidades de negócios (DEGEN, 1989).

Neste processo, após a observação das oportunidades e incentivos de mercado, a empresa deve observar quais serão os fatores laborais fundamentais em sua função de produção e, também, como será feita a combinação ótima destes fatores. Em outras palavras, os recursos escassos (tecnologia, informação, capital humano, etc.) devem ser gerenciados estrategicamente e, da interação desses recursos e processos é que se dará a produção dos bens e serviços, visando atender as demandas (necessidades e desejos) de qualidade, custo e tempo dos clientes. Portanto, os objetivos de produção estão fortemente atrelados com as necessidades de eficiência e eficácia da gestão de produção e operações (CORREA, 2005).

Nesse comenos, a Luthieria em estudo teve a peculiaridade de partir, em sua origem, de uma combinação com muito capital humano e poucas máquinas e ferramentas na produção dos primeiros instrumentos. $O$ que, como veremos neste artigo, alterou-se no decorrer do tempo para uma combinação "melhor" equalizada dos fatores utilizados na produção. Neste contexto, cabe a questão: qual seria a quantidade ótima de produção pra esta empresa? Stiglitz (2003), neste ínterim, nos sinaliza que a quantidade produzida depende, por um lado, do ponto de minimização dos custos de produção, isto é, da otimização da relação entre mão-de-obra, máquinas, matérias primas e demais insumos produtivos sob uma 
tecnologia de produção e por outro lado, da maximização do lucro: a otimização da quantidade vendida, buscando a maior receita possível dentro das restrições do tipo de mercado em questão.

Analisando o caso concreto e observando as orientações supracitadas, vê-se que a demanda pelos produtos da empresa estudada se dá por meio de encomendas e, para este tipo de produção, há sempre variações nos equipamentos/ferramentas, devido à diversidade de produtos demandados e pelo tamanho reduzido dos "lotes" fabricados (ZACCARELLI, 1979). Desse modo, para que se busque a otimização, segundo Palomino (2001), o sistema de produção deverá ser flexível para satisfazer pedidos que podem ser muito diferenciados, conforme o desejo dos clientes. Assim, pode-se dizer que a produção de empresas que produzem "sob encomenda" não possui homogeneidade, por seus produtos serem altamente customizados (EIDT, 2006).

Neste interim, Harding (1992) observa que, neste tipo de produção, o start se dá com um acordo entre empresa e cliente o que pode, à priori, acarretar na dificuldade de mensurar de maneira imediata o quanto de tempo e dinheiro será utilizado na preparação deste produto/serviço, já que as peculiaridades do produto são fornecidas pelo cliente e a empresa se incumbe de prestar conta encomendado levando em consideração o tempo de entrega, precificação, garantias, lucro etc. Do outro lado, a proposta entregue aos clientes devem conter informações suficientes sobre a habilidade do contratado que se incumbe do serviço em termos de qualidade e preço. Assim nasce, a partir da interação entre empresa e cliente, a idéia de criação de um produto totalmente novo, um simples concerto visando praticidade e preço ou até uma caracterização num produto já existente a fim de customizá-lo. 0 tipo de demanda dos produtos da Luthieria nos dá, também, o entendimento de como se procede ao nascimento e a evolução da empresa, que tende a transformar-se, quase que a cada encomenda diferente. Nesse "nascimento e transformação" é que está a base do empreendedorismo focado neste artigo.

Por fim, sumariando, veremos, no decorrer do trabalho, como o Luthier criou e modificou suas máquinas e ferramentas a fim de satisfazer os pedidos dos clientes, minimizando os custos e tornando viável o processo produtivo. Desse modo, a seção 3 , a seguir, irá demonstrar a metodologia utilizada na busca pelas informações que darão base à conclusão do artigo.

\section{Metodologia}

Tendo como foco principal o empreendorismo do Luthier Marcos Rosa em sua empresa de Campo Mourão - PR, o presente estudo, de natureza bibliográfico-conceitual e empírica e de abordagem qualitativa do trabalho de campo, se propõe a estudar e compreender o espírito empreendedor do empresário na sua busca por driblar as restrições financeiras e tecnológicas do seu próprio negócio. Sendo assim, serão especificados a seguir, os conceitos abordados, os instrumentos de pesquisa, os procedimentos para a definição da população e a definição de sua amostra, além do processo utilizado para a coleta e análise dos dados, suas virtudes e limitações, e algumas considerações de caráter geral sobre a validade da pesquisa.

A pesquisa bibliográfica utiliza-se de dados secundários, que são informações coletadas em sites, livros, revistas, jornais, etc., que segundo GIL (1999, p. 48) é "desenvolvida a partir de material já elaborado, constituído principalmente de livros e artigos científicos". Considerando esta pesquisa como bibliográfica-conceitual, será realizado estudo acerca das temáticas relacionadas à luthieria, empreendedorismo, restrições tecnológicas, função de produção, inovação, criatividade etc., e sobre a literatura brasileira referente à temática. Portanto, é um dos objetivos buscar pistas teóricas que contribuirão para dar mais rigor ao nosso estudo, como o grau de pertinência e validez de nossas hipóteses de trabalho.

A pesquisa empírica caracteriza-se como estudo de campo, o qual de acordo com Marconi e Lakatos (2003, p. 186), é utilizado "com o objetivo de conseguir informações e/ou conhecimentos acerca de um problema, para o qual se procura uma resposta, ou de uma hipótese, que se queira comprovar, ou, ainda, descobrir novos fenômenos ou as relações entre eles". Quanto a este estudo de campo e à utilização dos dados primários, para sua coleta foi utilizado um questionário com perguntas semi-estruturadas, que dará, ao mesmo tempo, aderência a questões fundamentais, como as expostas na fundamentação teórica e perspectivas de originalidade a partir do discurso do pesquisado, já que, como dissemos antes, a pesquisa, também, está mergulhada na subjetividade do empreendedor.

As entrevistas foram feitas na própria Luthieria através do Luthier Marcos Rosa no período entre Outubro e Dezembro de 2009. Foram utilizados papéis, canetas, vídeos e fotos demonstrados pelo pesquisado. Reunindo, além das técnicas necessárias para coleta de dados, as condições necessárias para o trabalho científico. Segundo Trivinõs (1987, p. 52): "a coerência, a consistência, a originalidade e a objetivação, por um lado, constituindo aspectos do critério interno da verdade, e, por outro, a intersubjetividade". 
Desse modo, o presente artigo é um estudo de caso com observação assistemática mais entrevista semi-estruturada. E a busca dos resultados permitirá demonstrar 0 empreenderismo do Luthier como base da viabilidade técnica/financeira da empresa.

\section{O Processo Criativo/Produtivo}

A visão comercial nasce para o Luthier Marcos Rosa em meados de 1999 ao fabricar seu primeiro instrumento de maneira artesanal: um violão. Este marco inicial dá base ao processo produtivo da empresa. Quando se observou, empiricamente, que havia uma demanda reprimida no segmento regional, em outras palavras, que havia uma oportunidade de negócio para o empresário onde este poderia fazer aquilo que se gosta e sabe fazer. Após tal constatação, a primeira restrição observada referiu-se aos limites técnicos e financeiros para a Luthieria produzir a custos que tornassem viável o processo produtivo no mercado em questão. Desse modo, era imperativo que o conjunto de produção fosse otimizado de modo paulatino, num processo produção/aprendizagem que se estendeu logo após o marco anunciado.

Interessantemente, em vista das restrições supracitadas, os primeiros passos para se adquirir potencial produtivo surgiram na criatividade e na incorporação de ferramentas nada convencionais para o ramo. No início das atividades a produção do corpo das guitarras, por exemplo, acontecia sem a utilização das máquinas que normalmente/comumente se utiliza na produção de instrumentos musicais. Pois, necessitava-se de uma fresadora com giro e corte que satisfizesse as condições básicas para o serviço, máquina que a empresa só conseguiu adquirir com adaptações e criatividade: combinou-se partes de outras máquinas criando-se uma nova máquina com capacidade suficiente para atender suas necessidades primárias:

A produção de início se dava com a utilização de furadeira e formão e deixava as bordas mascadas e irregulares comprometendo 0 acabamento e a apresentação do produto. A partir da necessidade de melhoria, foi desenhada uma máquina com fresas e gabaritos que facilitara o acabamento do produto. Apesar dessa máquina já existir no mercado, 0 projeto saiu apenas da imaginação do que seria necessário para conseguir produzir os instrumentos. 0 desenho foi levado para uma oficina de afiação de serras onde se produzia algumas máquinas e a partir de alguns ferros velhos, um motor de máquina de lavar e um mandril de furadeira foi criada a primeira máquina que melhoraria a produção da Luthieria (Luthier Marcos Rosa).

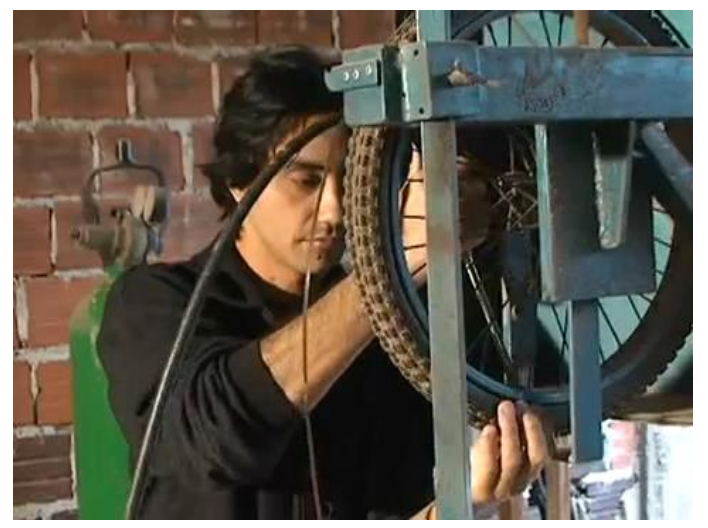

Figura $1-1^{a}$ máquina criada por Marcos Rosa.

Fonte: Acervo Marcos Rosa.

No entanto, com o decorrer do tempo a primeira máquina começa a se tornar obsoleta por não satisfazer os requisitos qualitativos demandados pelos clientes no que se refere ao acabamento dos instrumentos e, também, pelo risco que proporcionava ao Luthier, além do desperdício significativo de tempo pelo maior cuidado durante a sua utilização prejudicando os prazos de entrega do produto. Tornou-se, então, indispensável uma nova máquina que suprisse as novas demandas: maior segurança, melhor acabamento e menor tempo de produção: 


\section{Leandro Moreira Luz, Marcos de Matos Olioze e Rogério Silveira Tonet}

Outra adaptação foi feita por questão de melhoria e de segurança, já que a primeira máquina oferecia riscos. A produção nesse momento necessitava, cada vez mais, de giro e avanço para maior precisão no corte. Dessa vez, foi inventado algo como uma fresadora de topo que serve também como uma tupia invertida com copiador fixo tornando-a assim uma máquina multifuncional, tudo isso influenciado pela observação de máquinas utilizadas em marcenarias. Com a utilização dela é possível agora fazer cavaletes de violão, furos de captadores, rasgo de tensor, etc. Com essa nova máquina, houve também, uma diminuição do tempo de trabalho em aproximadamente 10 vezes (Luthier Marcos Rosa)

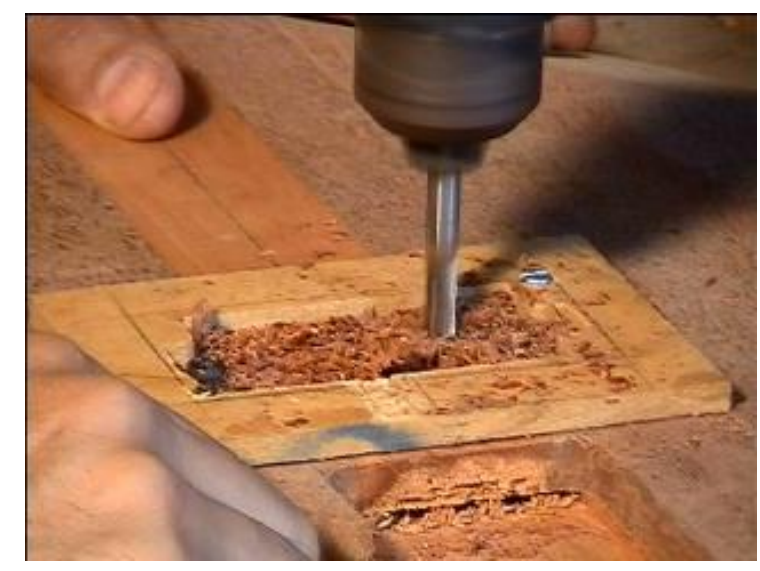

Figura $2-2^{\mathrm{a}}$ máquina: fresadora.

Fonte: Acervo Marcos Rosa.

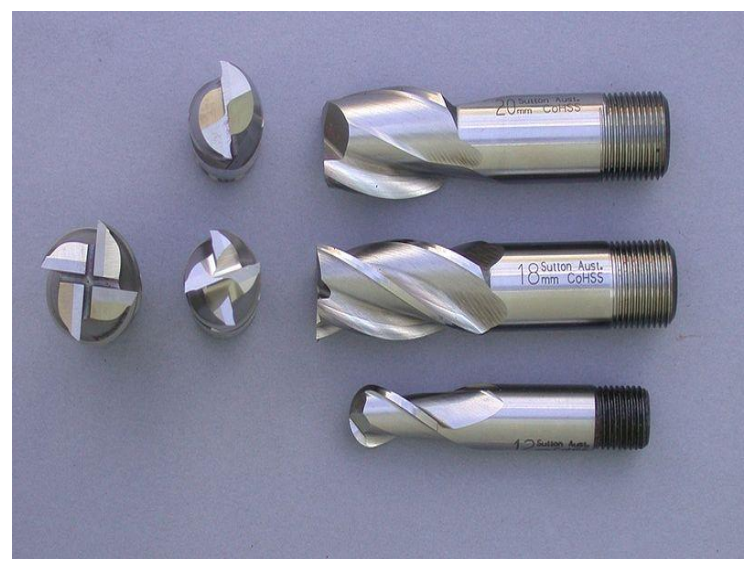

Figura 3 - Broca fresa.

Fonte: <pt.wikipedia.org>

Como pode ser observado nas figuras, as "invenções" do Luthier vão muito além da trivialidade no que se refere a uma Luthieria convencional. E, com o intuito de minimizar os custos, facilitar 0 acesso aos acessórios elétricos de captação do som dos instrumentos e, também, criar um diferencial nos produtos a empresa. Surge, então, a idéia da produção própria dos captadores utilizados nas guitarras, violões, etc.

Observando o funcionamento dos captadores industrializados, surge à idéia de fabricá-los na própria empresa, para aumentar os ganhos e criar um diferencial no produto. Foi feito experimentos com captadores de diversas marcas. A primeira análise foi no material utilizado na confecção desses captadores _ o tipo de fio utilizado na bobina, o modelo de bobina (como os fios são enrolados) e principalmente o tipo de imãs utilizados. Constatouse que as mínimas variações nesses materiais modificam o timbre captado do instrumento musical e que seria possível, com algumas técnicas, reproduzi-los artesanalmente utilizando madeira (Luthier Marcos Rosa). 


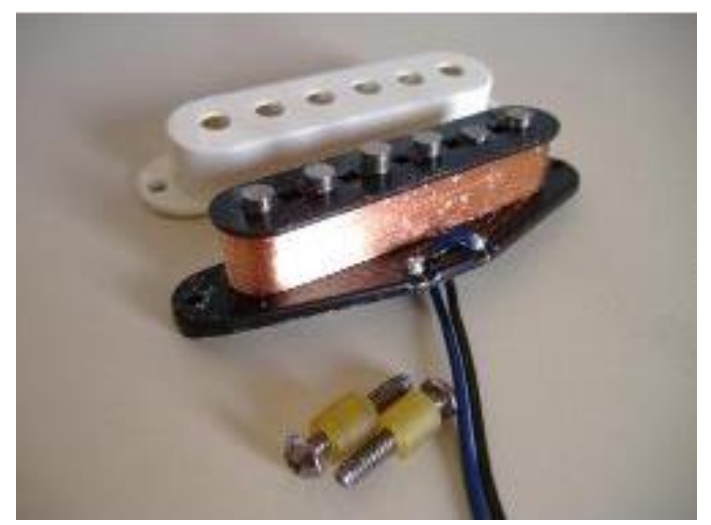

Figura 4 - Captadores industriais.

Fonte: <http://images.google.com.br>

Nesse ponto da produção, uma máquina para a confecção desses captadores era indispensável, uma vez que uma das particularidades do produto são as milhares de voltas que um fio de cobre tem que dar sobre um carretel imantado. Diante dessa restrição, criou-se então uma máquina a partir de um motor de máquina de costura associado a uma calculadora, e na medida em que o motor girava conta-se o número de voltas dos fios de cobre.

Nos captadores, o conjunto de quantidade de voltas, o tipo de imã e até o metal utilizado nas extensões polares modificam o timbre captado. Uma das particularidades mais interessantes é a quantidade de espiras que o fio de cobre dá em torno de um carretel com extensões polares imantadas. Essa quantidade de espiras gira em torno de 7.000 voltas e interfere além do timbre nas freqüências graves e agudas da captação. A maneira de contar essas voltas foi a criação de uma máquina a partir do uso de uma calculadora científica e um motor de máquina de costura com um pedal de controle. Aperta-se no número 1 e no sinal de adição da calculadora e a máquina bate no sinal de igual a cada giro do carretel e o operador gerencia o número de espiras (Luthier Marcos Rosa).

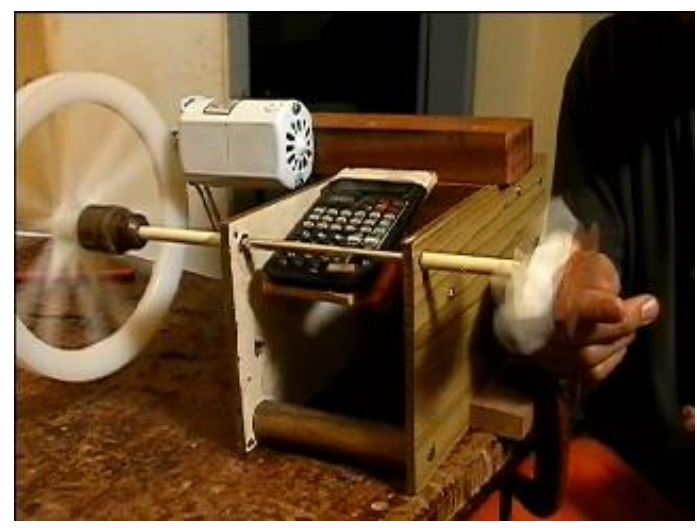

Figura 5 - Máquina de enrolar bobinas dos captadores.

Fonte: Acervo Marcos Rosa.

Além das máquinas necessárias para a produção o Luthier, em seu estado de arte, necessitava, também, de um conhecimento aprofundado sobre as matérias primas, em especial, as diferentes madeiras utilizadas na confecção dos instrumentos, é estritamente necessário para a obtenção de uma qualidade de som que diferencia o produto. 
O conhecimento das madeiras se dá pela observação, pelo olfato, pelo tato, etc. 0 gosto por madeira se deu desde a infância nas brincadeiras, nessa época já havia a busca de timbres diferentes batendo com a mão e ouvindo as diferenças de som de uma madeira pra outra. Pôde-se notar, através desta observação, que uma mesma arvore pode proporcionar tipos de madeiras diferentes para a construção de guitarras. Tanto a parte superior da árvore quanto as árvores mais jovens, por exemplo, a Maple _ oriunda do Canadá _ servem de matéria prima para as guitarras mais baratas, como a maioria das guitarras importadas comercializadas atualmente, proveniente na maioria da China, a parte mediana seria utilizada na produção de guitarras de renome e tradição como Fender, Ibanez etc. E a parte da base da Maple mais antiga, será utilizada em instrumentos de altíssima qualidade por proporcionarem timbres consistentes e excelente visual (Luthier Marcos Rosa).

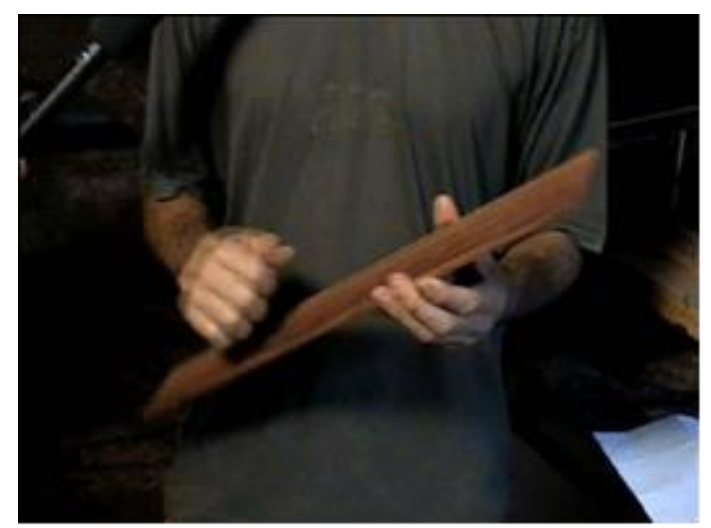

Figura 6 - Escala de Madeira em estado bruto (Jacarandá da Bahia).

Fonte: Acervo Marcos Rosa.

$\mathrm{Na}$ confecção dos violões, por exemplo, é utilizada uma série de madeiras distintas. No tampo utilizam-se madeiras mais leves e mais claras. Nas laterais e nos fundos usam-se madeiras mais pesadas e escuras. Nas escalas, madeira mais escura e mais densa, como o Ébano Africano ou como o Jacarandá da Bahia, como mostra a figura 6 , visto que as cordas provocam uma tensão sobre o braço do violão exigindo uma alta resistência mecânica, para evitar empenos e torções.

No caso do violão clássico de altíssima qualidade, por exemplo, no tampo utiliza-se 0 Pinho Sueco, a escala normalmente é em Ébano Africano, o braço pode ser de Cedro ou de Mogno, o fundo pode ser de Pau-Ferro, Jacarandá Indiano (Rose Wood) ou Jacarandá da Bahia e o cavalete de Jacarandá da Bahia. A utilização da madeira incorreta interfere diretamente na qualidade do instrumento (Luthier Marcos Rosa).

O Luthier comenta, também, quanto à obtenção das madeiras, uma matéria prima escassa e protegida por leis ambientais:

Busca-se, muito, madeiras recicladas e de "construções", reutilizadas de carrocerias de caminhão, depósitos com madeiras antigas estocadas aqui em Campo Mourão, sendo muito difícil de conseguir madeiras boas (Luthier Marcos Rosa). 


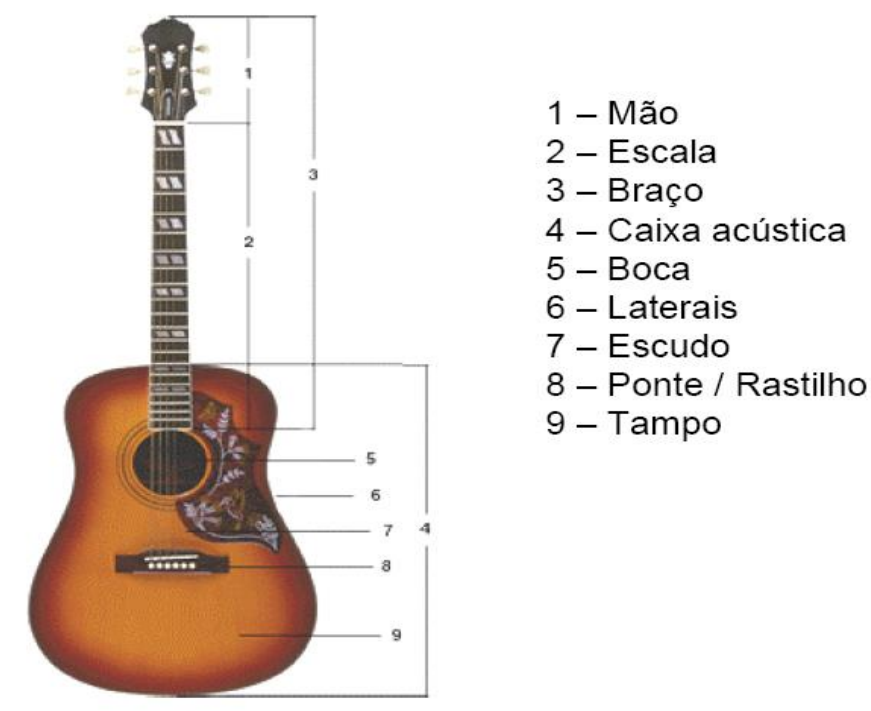

Figura 7 - 0 violão e seus principais componentes.

Fonte: <http://www.funtecg.org.br/arquivos/violao_final.pdf> acesso em 21 de outubro de 2009.

A maneira de interação entre matéria-prima, trabalho e máquinas nos revelam a tecnologia empregada para a confecção dos instrumentos musicais.

A natureza impõe restrições tecnológicas as empresas: somente algumas combinações de insumos constituem formas viáveis de produzir certa quantidade de produto, e a empresa tem de limitar-se a planos de produção factíveis (VARIAN, 2000).

O Luthier também descreve aqui um "mapa" que revela parte por parte sobre a produção de uma guitarra. No decorrer do processo é contratado um trabalho terceirizado, são empregadas quatro máquinas próprias, além de vários processos manuais, como coloca aqui o próprio Luthier Marcos Rosa:

Contrata-se uma empresa para plainar a prancha de cedro, depois faz-se um desenho da guitarra na madeira com uso de gabarito na para, em seguida, corta-la na serrafita. Passe na Tupia a lateral da guitarra saindo o Shape da guitarra praticamente pronto. Após isso faz-se o recorte dos captadores, braço e controle na fresadora de topo. E, por último, é feito o braço manualmente, e cortada a escala na serra elétrica com gabarito, colada no braço, posto os traste e marcadores. Pintada, polida e montada à mão (Luthier Marcos Rosa). 


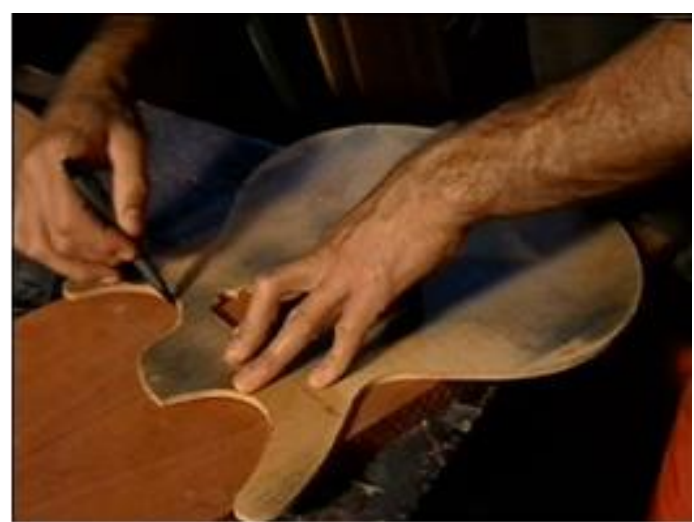

Figura 7 - Desenhando com gabarito.

Fonte: Acervo Marcos Rosa.

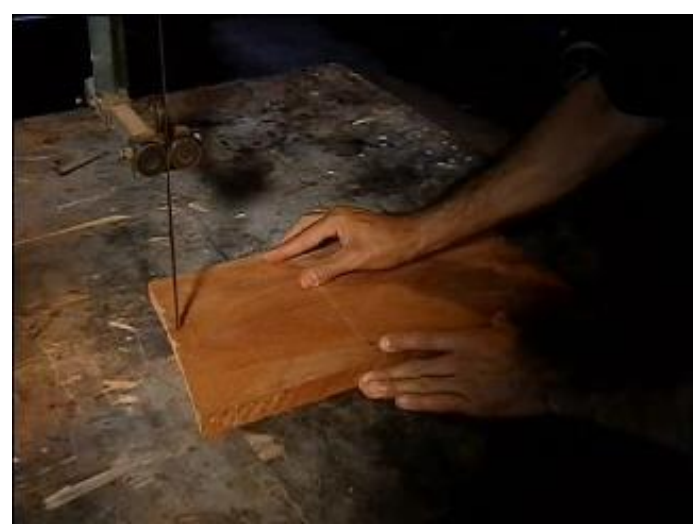

Figura 8 - Cortando na serrafita.

Fonte: Acervo Marcos Rosa.

Estes pontos sinalizados na entrevista com o Luthier Marcos Rosa trazem parte do dia a dia de sua empresa e a sua vontade/necessidade de construir o melhor instrumento musical para seus clientes. A produção de um instrumento musical, desde a escolha da madeira até os últimos acabamentos e testes é um todo interligado e indivisível. Além de que, a maneira como se produz vai trazer uma singularidade ao instrumento no qual o músico vai se identificar e é isso que fara do trabalho de um Luthier o seu referêncial. Deste modo, com criatividade, inovação e vontade o empresário transforma a todo o momento o seu modo de produção para um mercado consumidor técnico e inteligente.

\section{Considerações Finais}

O espírito empreendedor, que agrega iniciativa, visão, criatividade, inovação e predisposição para identificar oportunidades de negócio, colocados na revisão bibliográfica com Degen (1989), Byrley e Muzyka (2001) e demais teóricos, evidencia-se nos relatos da entrevista cedida pelo Luthier e na observação assistemática dos pesquisadores.

A singularidade evidenciada na criação das máquinas, modelos de produção, tecnologias alternativas para alcançar 0 produto com a qualidade desejada, visão de mercado buscando a renovação constante das informações sobre os insumos produtivos, em suma, satisfez o desejo e os objetivos analisadores e classificadores do artigo, este que, se propôs em buscar um espelho de empreendedorismo na figura de Marcos Rosa enquanto proprietário e artífice de uma Luthieria.

Dessa maneira, é certo concluir a partir da literatura estudada e da entrevista e visita à campo que esta Luthieria tem por alicerce o empreendedorismo: pois esta é reconhecida pela ousadia acima da média e competência para transformar "algo" numa oportunidade de gerar produtos/riqueza, com características principais pautadas na iniciativa e a inovação no que se refere às máquinas e aos processos produtivos. 


\section{Referências Bibliográficas}

ANGELUCCI, Thalita Camargo; SCOPINHO, Rosemeire A. O Espaço da cultura na Luta pela Reforma Agrária: Meandros do Encontro Nacional de Violeiros.2007. Tese de Doutorado. Universidade Federal de São Carlos.

BIRLEY \& MUZYKA. Dominando os Desafios do Empreendedor.Tradução de Cláudio Ribeiro de Lucinda. Revisão Técnica de David Felipe Hastings. São Paulo: Makron Books, 2001.

CORRÊA, Henrique L; CORRÊA, Carlos A. Administração de Produção e operações: manufatura e serviços: uma abordagem estratégica. Tradução de Cláudio Ribeiro de Lucinda. Revisão Técnica de David Felipe Hastings. São Paulo: Makron Books, 2001.

DEGEN, Ronald Jean. Fundamentos da Iniciativa Empresarial.Colaboração de Álvaro Araújo Mello. Makron Books. São Paulo, 1989.

DRUCKER, Peter Ferdinand. Inovação e espírito empreendedor.Cengage Learning Editores, 2000.

EIDT, J. Gestão de custos em indústrias do setor moveleiro estabelecidas no Oeste de Santa Catarina: um estudo multicasos. 233 f. Dissertação (Mestrado em Ciências Contábeis) - Programa de Pós-Graduação em Ciências Contábeis, Universidade Regional de Blumenau - FURB, Blumenau, 2006.

GIL, A. C. Como elaborar projetos de pesquisa. 4. ed. São Paulo. Atlas, 2001.

HALL, Robert E. Microeconomia: Princípios e Aplicações. Tradução Luciana Penteado Miquelino; Revisão Técnica Carlos Roberto Martins Passos. São Paulo: Pioneira Thomson Learning, 2003.

HARDING, Hamish Alan. Administração da Produção.Tradução de José Marques Jr. Atlas. São Paulo, 1992.

PALOMINO, R. Um modelo para o planejamento e a programação da produção em ambientes job shop baseado em redes de Petri. Tese (Doutorado). Universidade Federal de Santa Catarina. 2001.

RICHARDSON, R. J. Pesquisa Social: métodos e técnicas. 3. ed. São Paulo. Atlas, 1999.

SOUZA, Antônio A. Gestão de Custos em Empresas de Produção por Encomenda. Universidade Federal de Santa Catarina - Centro de Tecnologia. Disponível em http://www.ingepro.com.br/index.php/ingepro/article/viewFile/51/47. Acesso em 08 de Janeiro de 2010.

STIGLITZ, Joseph E; WALSH, Carl E. Introdução à Microeconomia Tradução Helga Hoffmann;. São Paulo: Pioneira Thomson Learning, 2003. D

TRIVIÑOS, A.N. S. Introdução à pesquisa em ciências sociais: a pesquisa qualitativa em educação. São Paulo: Atlas, 1987

VARIAN, Hal R. Microeconomia. Princípios Básicos. Tradução da 5.ed. americana Ricardo Inojosa, Maria José Cyhlar Monteiro. Rio de Janeiro Campus, 2000

ZACCARELLI, S. B. Programação e Controle da Produção. 5. ed. São Paulo: Pioneira, 1979. 